\title{
Analysis of the distribution of maxillary stresses submitted to surgically assisted rapid maxillary expansion with a bone-supported device
}

\author{
Análise da distribuição das tensões em maxila submetida à expansão cirurgicamente assistida com \\ aparelho ósseo-suportado
}

Análisis de la distribución de tenciones en maxilares sometidos a expansión rápida asistida quirúrgicamente con un dispositivo de soporte óseo

\begin{abstract}
The objective of the research was to evaluate the distribution of stress produced by surgically assisted rapid maxillary expansion in the maxillary structures using the bone-supported expander device by the Finite Element Method. Material and methods: A three- dimensional model was simulated for surgery with a LeFort I osteotomy with pterygomaxillary disjunction using a bone-supported device model for the $1 \mathrm{~mm}$ aperture. The results showed a greater opening of the maxilla in the anterior region and a smaller opening in the posterior region. The tension forces showed mainly in all the palatine face and the posterior alveolar bone and tuber, as well as in the epilating zygomatic region above the osteotomy. The stress showed little dissipation for the roots of the molar. The forces of compression were manifested in the pterygoid process and the zygomatic pillar adjacent to the osteotomies, as well as in the expander areas of contact with the palatine bone. The analysis showed that the most stressed part is the rod connecting the device module to the support platform. Conclusion: The resulting tension stresses transmitted to the alveolar bone of the teeth adjacent to the appliance did not seem to be sufficient to displace the teeth.
\end{abstract}

Keywords: Palatal expansion technique; Finite element analysis; Dental stress analysis.

\section{Resumo}

O objetivo desta pesquisa foi avaliar, por meio do Método de Elementos Finitos (MEF), a distribuição das tensões produzidas pela Expansão de Maxila Cirurgicamente Assistida (EMCA) nas estruturas maxilares utilizando-se aparelho expansor ósseo-suportado. Material e métodos: Foi confeccionado um modelo tridimensional de maxila para simulação da EMCA com osteotomia tipo LeFort I descendente sem degrau, com disjunção pterigomaxilar utilizando um modelo de aparelho ósseo-suportado para o teste com a simulação de abertura de $1 \mathrm{~mm}$. Os resultados mostraram maior abertura da maxila na região anterior de incisivos a pré-molar $(1 \mathrm{~mm})$ e em menor quantidade $(0,6 \mathrm{~mm}) \mathrm{na}$ região de molares. A tensão máxima principal (TMXP) mostrou a concentração de tensões principalmente em toda 
face palatina da maxila de pré-molar ao túber maxilar. Pela face lateral, ficou mais evidente a TMXP nas regiões de osso alveolar posterior ao pré-molar, molares e túber, assim como na região de pilar zigomático acima da osteotomia. Pelo plano transversal foi possível observar a transmissão de tensões ao longo das estruturas ósseas mostrando pouca dissipação para as raízes do molar. Enquanto que as forças de compressão (Tensão Mínima Principal), evidenciadas pela tensão mínima principal, se manifestaram nas áreas de pilar zigomático e adjacentes as osteotomias, assim como nas áreas de contato do apoio do aparelho com o osso palatino. Tensões de tração e compressão também foram evidenciadas na região de processo pterigoide. A análise de tensão de Von Mises mostrou que a parte que mais sofreu estresse é a haste que liga o módulo do aparelho com a plataforma de apoio. Conclusão: Houve maior abertura da maxila na região anterior e as tensões resultantes de forças transmitidas ao osso alveolar dos dentes adjacentes ao aparelho, parecem não ser suficientes para deslocar os dentes.

Palavras-chave: Técnica de expansão palatina; Análise de elementos finitos; Análise do estresse dentário.

\section{Resumen}

El proposito de este estudio fue evaluar la distribución del estrés producido por la expansión maxilar rápida asistida quirúrgicamente en las estructuras maxilares utilizando el dispositivo expansor soportado en hueso por el Método de los Elementos Finitos. Material y métodos: Se simuló un modelo tridimensional para cirugía con osteotomía LeFort I con disyunción pterigomaxilar utilizando un modelo de dispositivo de soporte óseo para la apertura de $1 \mathrm{~mm}$. Los resultados mostraron una mayor apertura del maxilar en la región anterior y una menor apertura en la región posterior. Las fuerzas de tensión se manifestaron principalmente en toda la superficie palatina y el hueso alveolar posterior y tubérculo, así como en la región de pilar cigomático por encima de la osteotomía. El estrés mostró poca disipación para las raíces del molar. Las fuerzas de compresión se manifestaron en el proceso pterigoideo y el pilar cigomático adyacentes a las osteotomías, así como en las áreas de contacto del expansor con el hueso palatino. El análisis de tensión de Von Mises mostró que la parte que sufrió más tensión es la varilla que conecta el módulo del dispositivo con la plataforma de soporte. Conclusión: Los esfuerzos de tensión resultantes transmitidos al hueso alveolar de los dientes adyacentes al aparato no parecen ser suficientes para desplazar los dientes.

Palabras clave: Técnica de expansión Palatina; Análisis de elementos finitos; Análisis del estrés dental.

\section{Introduction}

Surgically Assisted Rapid Maxillary Expansion (SARME) is an alternative for the treatment of transverse maxillary deficiency. In this modality, after surgery, the main points of maxillary reinforcement are removed, the expansive movement is performed gradually by dento-supported, dento-muco-supported, implanto-supported or osseo-supported with effects on the craniofacial skeleton that go beyond the simple uncrossing of the arches (Bishara et al., 1987; Bays et al., 1992; Babacan et al., 2006; Gonçales et al., 2007; de Assis et al., 2011; Assis et al., 2013).

Changes in the configuration of osteotomies, the type of expander device and the rate of activation have a great impact on the success and morbidity of the treatment. Some complications include: root resorptions, inclinations of the supporting teeth of the expanders, dental extrusions, inadequate expansion, undesirable bone fractures, gingival recessions, loss of bone between the incisors and even failure to expand (Bell et al., 1976; Schwarz et al., 1985; Bays et al., 1992; Basdra et al., 1995; Gerlach et al., 2005; Babacan et al., 2006; Williams et al., 2012).

Some studies have evaluated the effects of SARPE by comparing models of studies of individuals submitted to SARPE in the pre and postoperative period and its effects on inclination, rotation and movement of teeth in the maxillary arch (Chung et al., 2003; Seeberger et al., 2010; Kilic et al., 2013).

Because of its characteristics and properties, the finite element method (FEM) has been one of the tools used by some authors to assist in the analysis of the behavior of craniofacial structures of individuals with skeletal facial deformities when submitted to surgically assisted rapid maxillary expansion, especially with respect to the comparison between different surgical techniques and the types of expanders (Jafari et al., 2003; Shetty et al., 2009; Boryor et al., 2010; Gonçales, 2011; de Assis et al., 2014).

Even though the FEM is part of a well-established study model in assessing the behavior of bone and dental structures versus dento-supported and dento-supported devices, standardized clinical trials regarding the use of palatine distractors are rarely found. 
The aim of the present study was to evaluate, through the finite element method, the stress distribution pattern of SARME on maxillary structures using a bone-supported device.

\section{Methodology}

For the present research, a hemi-maxilla model was constructed considering a hypothesis of symmetry, so loading and results for the left and right side were identical. The simulated materials were considered isotropic, elastic, linear and homogeneous, that is, they are materials that have the same properties when subjected to the application of forces in all directions. The model was composed of cortical bone, teeth, mucosa and steel. The main properties of the simulated materials are described in Table 1.

Table 1: Isotropic mechanical properties of the simulated materials.

\begin{tabular}{llc}
\hline Structures & Young's Modulus / Elasticity (E) & Poisson coefficient \\
\hline Cortical bone & $17,5 \mathrm{GPa}$ & 0,3 \\
Tooth & $20 \mathrm{GPa}$ & 0,3 \\
Mucosa & $0,2 \mathrm{GPa}$ & 0,45 \\
Steel & $210 \mathrm{GPa}$ & 0,3 \\
\hline
\end{tabular}

Source: Unit of measurement: GPa (Giga-Pascal). Adapted from de Assis et al., (2014).

After the importation of the geometry of the anatomical model of the simplified and deformed maxilla, a finite element mesh was generated with 279,419 tetrahedral elements and 432,828 nodes.

\section{Characteristics of the expander device}

The device considered was a bone-supported distractor, anchored in the maxilla through two screws. Because it is a simplified simulation, in which the program itself stipulates the contacts between the parts, the construction of the geometry of the screws did not consider the representation of the turns and the thread steps that compose them.

The fixing screws of the device in the maxillary bone were positioned in the most neutral position possible, with the main role of stabilizing the device, thus leaving the distribution of the tensions to the rest of the device.

The device was positioned over the medial palatine suture, fixed in the palatal region of the maxilla bones between the 1st premolar and the 1st molar (Figure 1). They were the only posterior teeth kept in the model so as not to overload mathematical information in the software, and kept as fixed abutments in the maxilla without the presence of periodontal ligament in the condition of ankylosis. 
Figure 1 - Anchorage location of the bone-supported device.

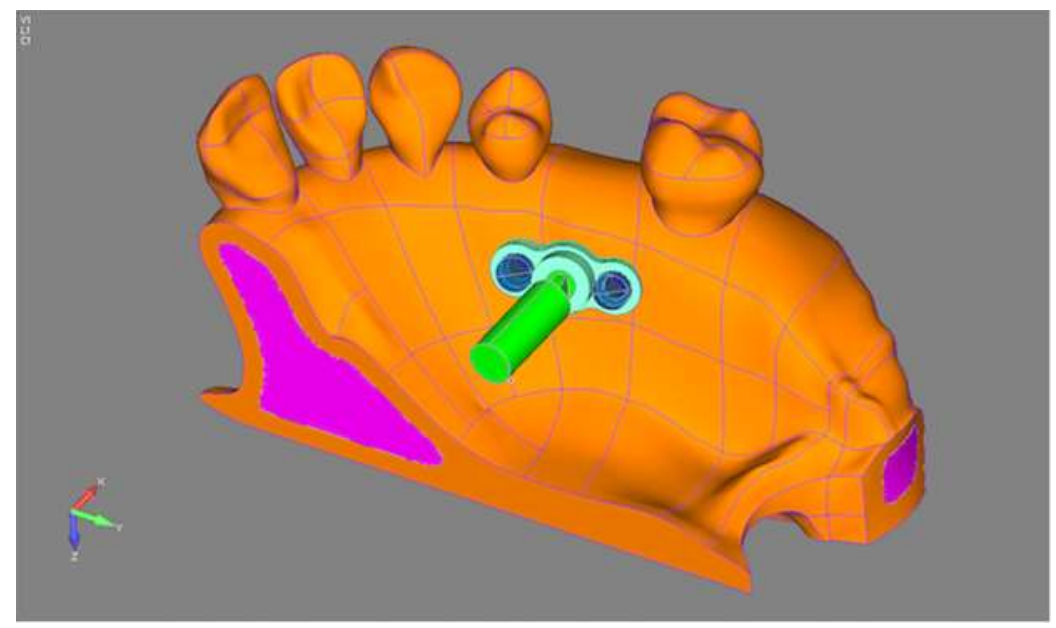

Source: Authors.

\section{Expansion simulation}

The osteotomy was the Le Fort I subtotal straight, descending, with separation of the medial palatine suture and rupture of the pterygoid process.

Friction between the contacts of the surfaces in the osteotomies was not considered, which were limited to a distance that simulated a cut "gap" equivalent to $1 \mathrm{~mm}$.

The distance set for the activation of the expander device was $0.5 \mathrm{~mm}$, that is, $1 \mathrm{~mm}$ of expansion considering the movement of the two segments of the maxilla. At this distance, the maximum Von Mises stress of the metal of the expander device would be in a value close to the conventional flow limit of the steel.

A nonlinear model was adopted for the analysis to contemplate large displacements in more advanced contact models.

\section{Finite element analysis}

The interpretation criteria for the present study followed established criteria, being the von Mises stress analysis (applied for static strength of ductile materials) and Maximum Principal Stress (MPS) (applied to friable materials such as bone structures).

The results obtained from the load distributions (minimum principal stress, maximum principal stress and Von Mises stress) and displacement were analyzed in a descriptive way by means of a color scale map representing the value in MegaPascal (MPa) of the stresses exercised.

\section{Results}

\section{Displacement pattern}

The amount of displacement of the model in the $\mathrm{X}, \mathrm{Y}$ and $\mathrm{Z}$ axes is represented by color distribution fields, with the red color being the largest displacement and the dark blue color being the non-displacement. This color / displacement ratio can be seen on the graduation scale next to the images.

The greater degree of displacement of the model can be observed in Figures 2 and 3, showing that the anterior part of the maxilla in the region of the canine incisors was the segment that most suffered movement during the simulation. The color map shows the regions in red that have suffered maximum displacement, corresponding to approximately $0.5 \mathrm{~mm}$. 
Figure 2: Occlusal view of displacement analysis on the $\mathrm{X}$ axis $(\mathrm{mm})$. Proposed displacement of $1 \mathrm{~mm}$.

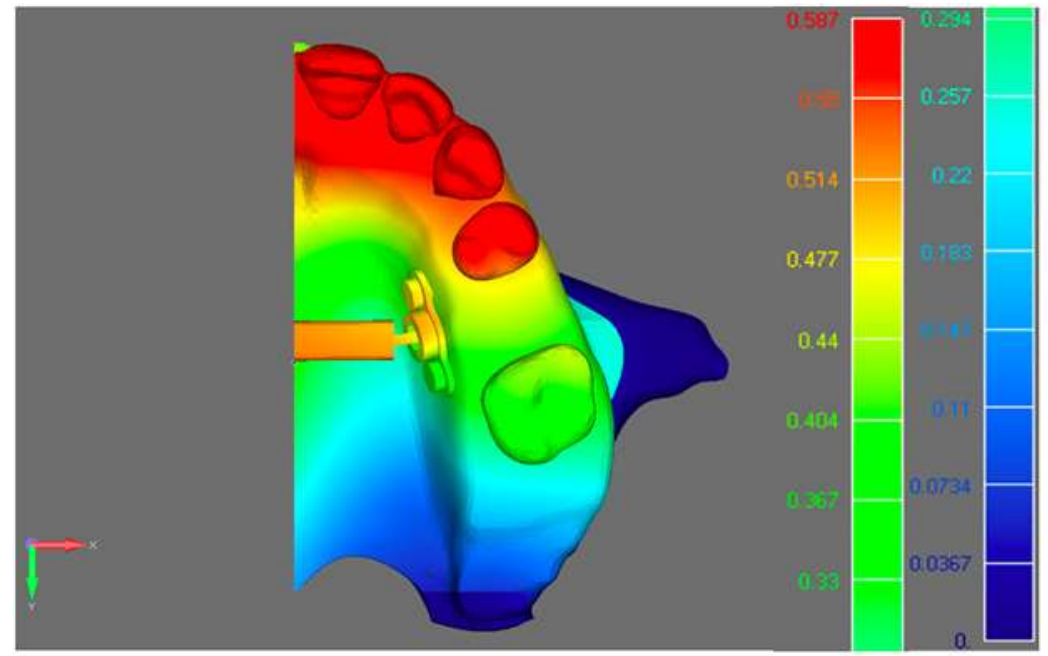

Source: Authors.

Figure 3: Front view of the $\mathrm{X}$-axis displacement analysis model (mm). Scale from 0 to $0.58 \mathrm{~mm}$.

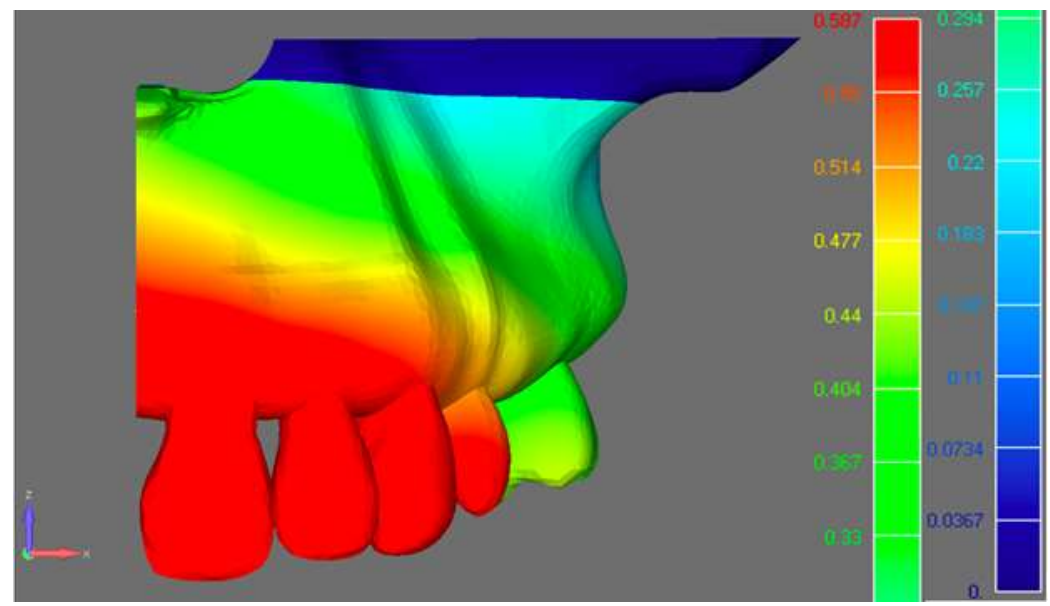

Source: Authors.

\section{Tension distribution pattern}

\section{Maximum Principal Stress - MPS}

The evaluation of MPS is used to evaluate and evidence the regions corresponding to tensile stresses. For the evaluation of the MPS, a color map graduation was used, in which positive values correspond to the tensile stress and negative values to the compression stress.

The MPS showed higher tensile stresses in the vestibular alveolar bone, in the region of the premolar and molar borders, corresponding to the region of support of the expander device. Concentration in the small regions adjacent to the osteotomy was also evidenced in the areas near bone reinforcements such as the canine pillar, zygomatic pillar and pterygomaxillary suture. (Figure 4)

There is a distribution of stresses distributed throughout the alveolar bone and palatine process in the palatal region, from the region of the premolars to the posterior region, except in the region that corresponds to the support of the expander device, in which there was a higher concentration of compressive stresses. (Figure 5)

According to the negative values of the color map scale, it was possible to observe a higher concentration of 
compression in the regions above the alveolar bone, especially in the zygomatic pillar region in the mobile segment of the maxilla, also affecting the area of the osteotomy (Figure 5).

A concentration of compression stresses was observed at the support site of the distractor device, between the perforations of the screws, more specifically towards the posterior perforation. These forces seem to dissipate as they move away from the insertion site of the device (Figure 5).

Still by palatal view, a concentration of these stresses was observed in the fixed part of the model, along the line of the osteotomy, evidencing the possible points of contact between the parts (Figure 5).

In a transverse view, observing the relationship of the alveolar bone with the roots of the teeth of the model, we can observe a higher concentration of tensile stresses dissipating from the palatine side to the vestibular side through the alveolar ridge, transmitted mainly to the 1st molar palatine root and for a small portion of the cervical region of the teeth (Figure 5).

Figure 4: Side view of the model of the Maximum Principal Stress observed in the alveolar bone region and around the zygomatic process, highlighted. Scale from -20 to $20 \mathrm{MPa}$.

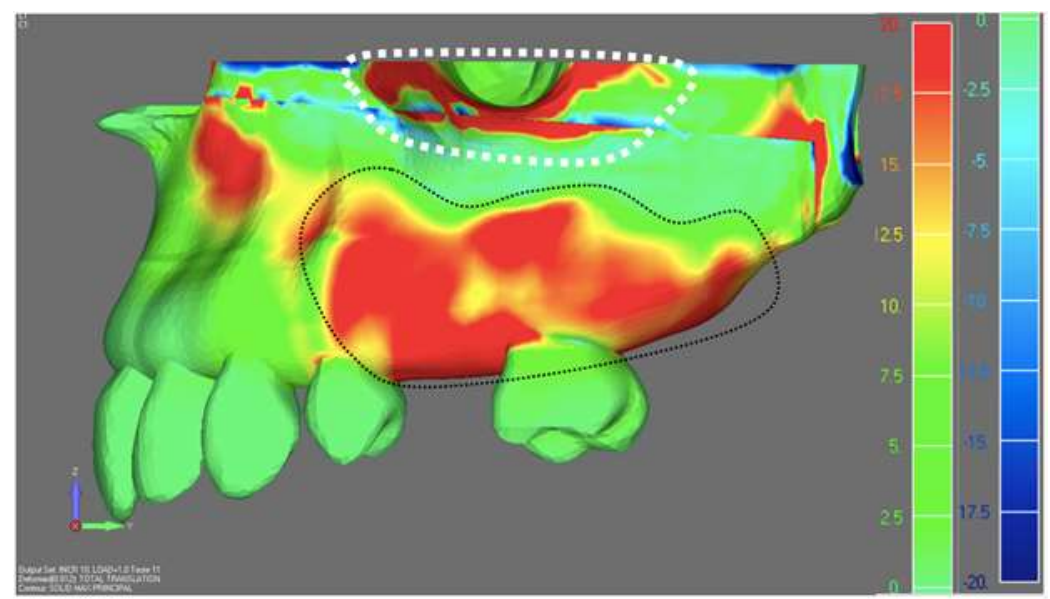

Source: Authors.

Figure 5: Anteroposterior palatine view of the Maximum Principal Stress model observed in the palatal process region at $1^{0} \mathrm{PM}$. Scale from -20 to $20 \mathrm{MPa}$.

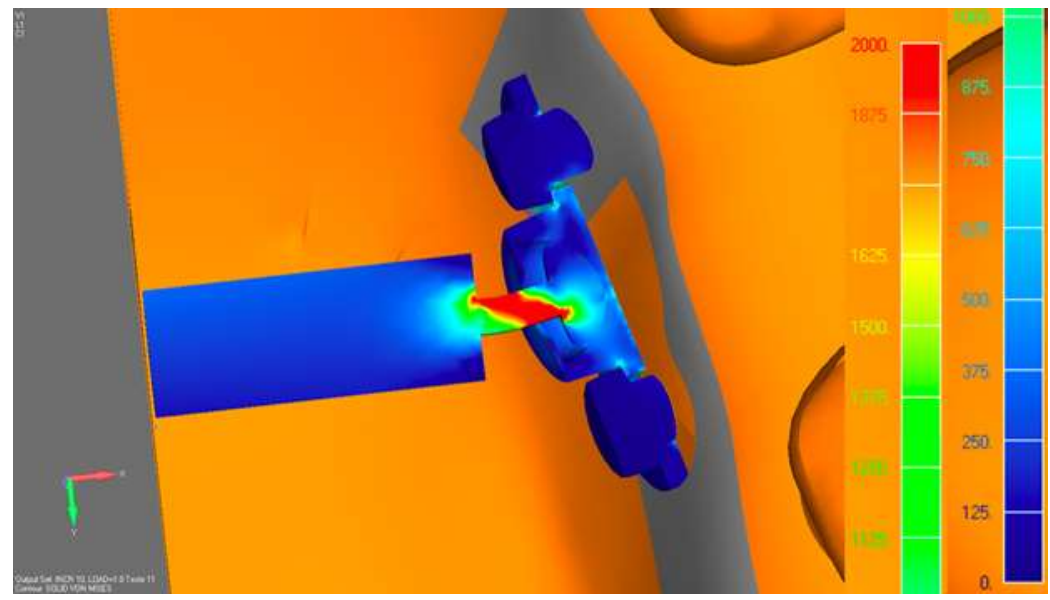

Source: Authors. 


\section{Minimum Primary Stress - MnPS}

The minimum primary stress (stress that evidences the areas of compression) is characterized by the bluer color, according to the negative values of the color map scale. It was possible to observe a higher concentration in the regions above the alveolar bone, especially in the zygomatic pillar region, both in the mobile segment of the maxilla and in the fixed segment, tangentiating the area of the osteotomy (Figure 6).

Figure 6: Side view of the model of the Minimal Principal Stress observed in the upper region of the alveolar bone adjacent to the zygomatic process. Scale from -150 to $131 \mathrm{MPa}$

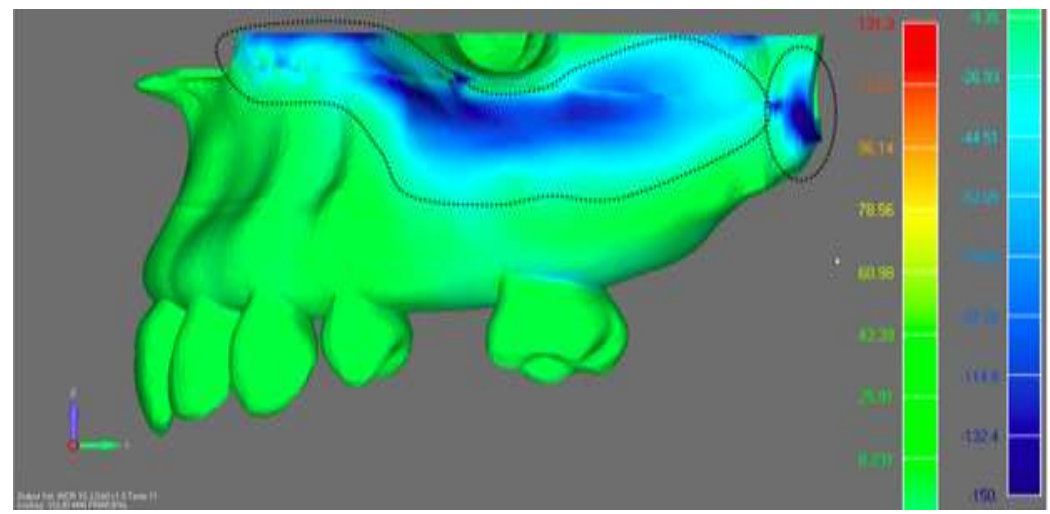

Source: Authors.

In the palatal region, a concentration of MnPS was observed at the distal device support site, between the perforations of the screws, more specifically toward the posterior perforation. These forces seem to dissipate as they move away from the insertion site of the device (Figure 7).

Still by palatal view, a concentration of these forces was observed in the fixed part of the model, along the line of the osteotomy, evidencing the possible points of contact between the parts (Figure 7).

Figure 7: Palatal view of the Minimal Principal Stress observed in the region of support of the distractor and along the bone structures adjacent to the osteotomy. Scale from -150 to $131 \mathrm{MPa}$.

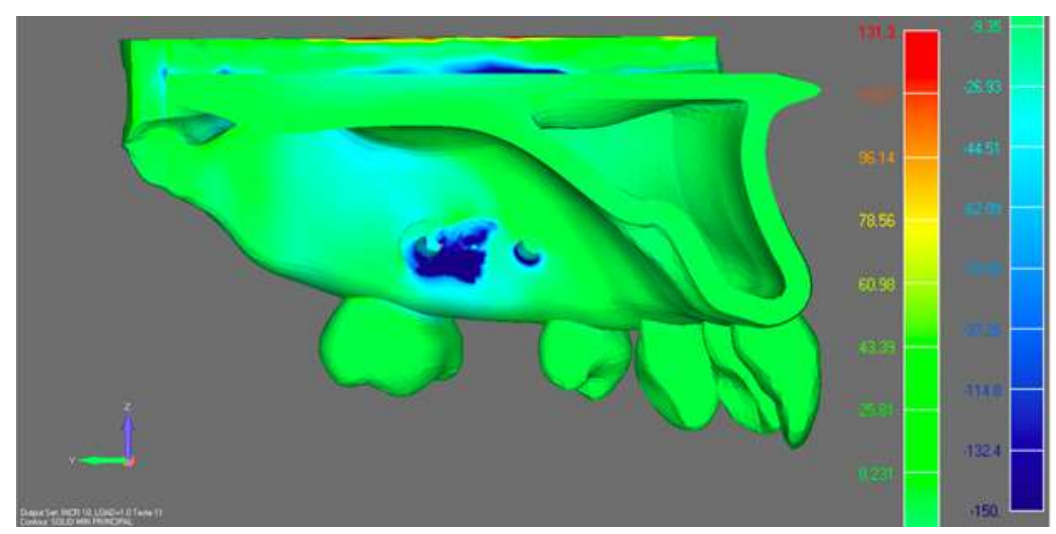

Source: Authors.

\section{Von mises stress}

Static strength of ductile materials was applied. In general, greater stress is observed in the rod of the expander device that makes the connection of the body with the joint part of the extremity (Figure 8). With less intensity, stress was evident on 
the surface of the device that is in contact with the maxilla, more specifically in the central region (Figure 9).

Figure 8: Von Mises stress observed on the expander device stem. Scale from 0 to $2000 \mathrm{MPa}$.

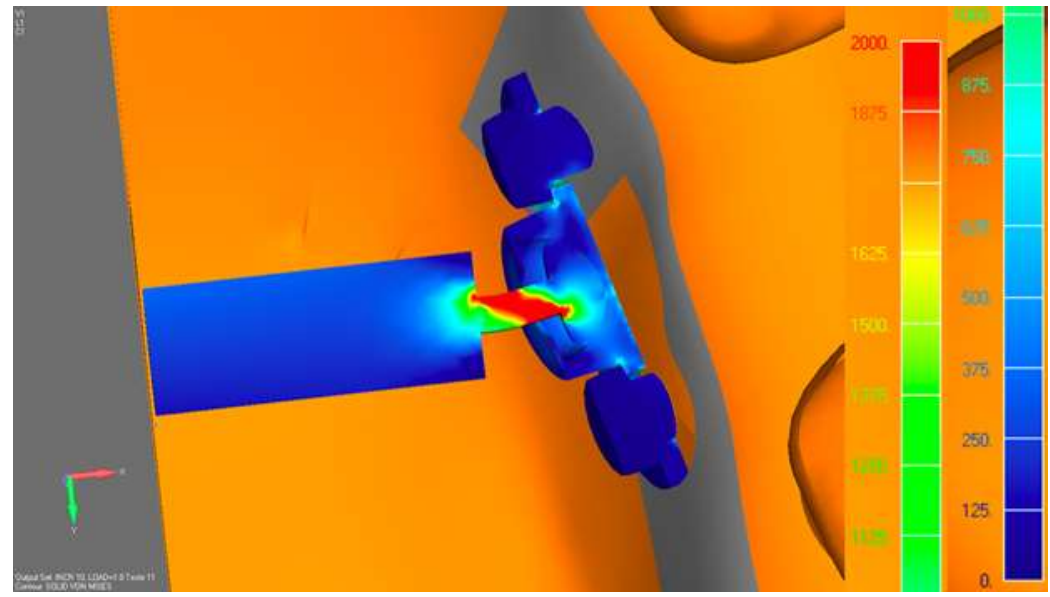

Source: Authors.

Figure 9: Von Mises stress observed on the expander device. Scale from 0 to $2000 \mathrm{MPa}$.

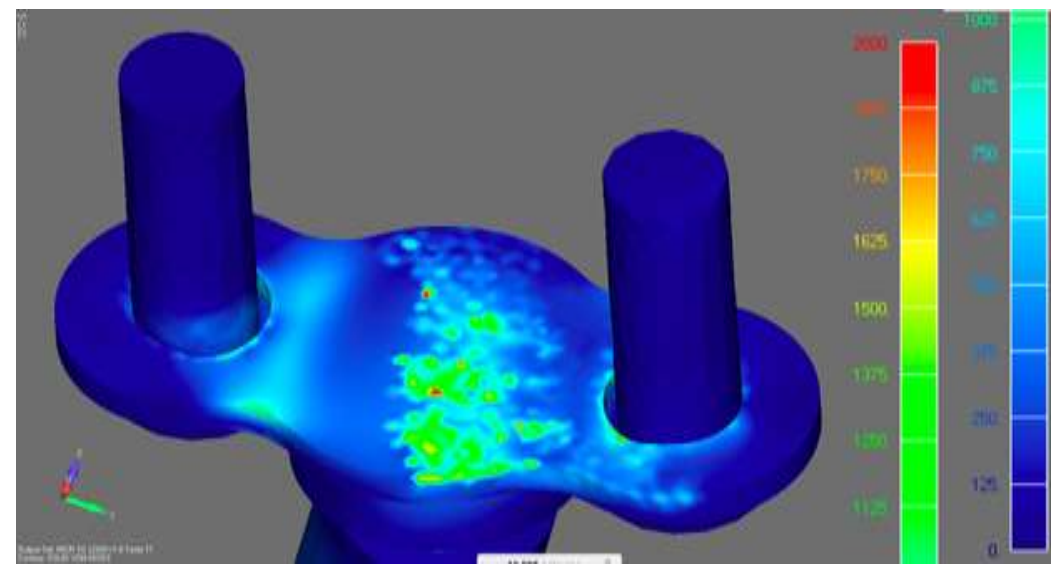

Source: Authors.

\section{Discussion}

According to Haas (1961), the dissipation of the forces generated when using a dento- muco-supported device is done in a more uniform way, distributed by the alveolar bone, fibers of the periodontal ligament and palate. Thus, it is a maximum anchoring device whichgenerates less damage to the supporting teeth than when compared to the dento-supported device in the maxillary expansion process.

The literature shows that the undesirable effects related to SARME are directly related to the pattern of distribution of tensile forces exerted through the different types of distractors for the maxillofacial structures. This transmission of forces generated by the expansion, when dissipated through devices with dental support, can generate undesired movements of the same (Koudstaal et al., 2009; Verstraaten et al., 2010).

It is understood that the greater the distribution of stresses to the teeth, the greater the displacement and inclination of the teeth and consequently, the greater the probability of relapse of the obtained expansion, considering this as a dental recurrence, not a skeletalrecurrence. Therefore, it is important to emphasize that the choice of the type of device usedhas a great influence on such effects of the SARME (Gonçales, 2011; de Assis et al., 2014). A tooth borne distractor may cause 
orthodontic movement and with could lead to fenestration of the teeth, periodontal problems, gingival recession, resorption of roots, and dental tipping. Still, the bone borne distractor can cause rotation of the segments and asymmetrical widening (Aziz \& Tanchyk, 2008; de Gijt et al., 2017).

Seeberger et al., 2010 observed a "V" -like movement of the segments, with a greaterexpansion in the anterior region of the maxilla studying individuals submitted to SARME without the disjunction of the pterygomaxillary suture. Although our study model simulated the pterygomaxillary disjunctions, we also observed a similar initial opening pattern, with a greater transverse movement in the anterior region (approximately $1 \mathrm{~mm}$ ) when compared to the molar region (approximately $0.6 \mathrm{~mm}$ ). Corroborating with the systematic review by Verstraaten et al., 2010 who observed a tendency of the maxilla to suffer greater expansion in the anterior part with a " $v$ " opening occurring when the device was anchored in the regionof the second premolars, and without the surgical disjunction of the pterygoid process.

Möhlhenrich et al., 2021 studied the influence of distractor position on surgically assistedrapid palatal expansion with or without pterygomaxillary disjunction, and they concluded that the disjunction of the pterygomaxillary suture appears to play a more important role in achieving a uniform and parallel transverse expansion of the maxilla than the position of the distractor, provided it is placed at the same level on both sides of the palate.

The studies conducted by Shetty et al., 1994 and Shetty et al., 2009 using the FEM showed that the concentration of maximum principal stress distributed on the bone tissue is in the palatal region of the central incisors. Such data may justify the openness pattern observed in the present study. As a result of this stress in the incisor region, Holzinger et al., 2021 suggest that stress should not be applied to the incisors within 6 months of surgery, regardless of the protocol used, as bone density between the incisors decreases with progressive distraction.

Comparing our results with those of de Assis et al., 2014, considering the displacement analysis, we found that in both models, where there was a separation between the maxilla and the pterygoid process, there is a sudden change in the color tone, characterizing a greater freedom of posterior movement of the maxilla when the pterygomaxillary disjunction was performed.

The present study evaluated the same stress dissipation in a model adapted from de Assis et al., 2014, who evaluated dento-muco-supported devices, relating the bone-supported device to straight osteotomy, descending and disjunction of the pterygomaxillary suture. Differently from these authors, the model used demonstrated a higher concentration of stresses in the alveolar bone region, especially in the posterior region of the premolar to the tuberosity region, however, with a lower distribution of stresses to the adjacent teeth.

Thus, the advantage in the choice of the bone-supported device is suggested since the stresses that dissipate in the bones tend to affect the teeth near the anchorage region of the device, which can clinically mean less tooth movement. Since the dissipation of stresses in the periodontal ligament caused by dental anchors decreases, the stress transmitted to the alveolar process and consequently, the inclination of the teeth also decreases (Bishara \& Staley, 1987; Gauthier et al., 2011).

Such a pattern of stress dissipation may also be related to the inclination tendency of the maxillary bone segments with greater transverse opening in the border region comparedto the floor region of the nasal cavity, as reported by Zandi et al., 2016 and Asscherickx et al., 2016.

With a study model quite similar to the present study, de Assis et al., 2013 were able toshow, in one of their models (M5), the distribution of stress and compressive stress dissipating from the dento-muco-supported device to the supporting teeth and consequently to the facial skeleton. With these results it has been proven that such stresses can cause dental movements of the supporting teeth, thus increasing the risk of dental complications. In contrast, the present study using the 
same FEM model, with the preparation of the palatine bone distractor, proved that the dissipation of the stresses and compression stresses are distributed with greater intensity of the device to the alveolar bones and, more comfortably, by the teeth adjacent to the device supports. Therefore, when reducing stresses distributed to the teeth, the bone-supported device may be more useful in reducing the dental complications of the SARME, as well as in the rate of dental recurrence. Associated with this, the combination of the Le Fort I subtotal osteotomy with the intermaxillary suture osteotomy and with the disjunction of the pterygomaxillary processshould be the osteotomy of choice aiming at the same purpose.

The difficulty in carrying out a study with all the characteristics suitable for a thoroughevaluation of the effects of the SARME comparing surgical techniques and the types of devices used, make FEM a viable simulation tool accessible to the dentist who becomes reliable with time. Therefore, it is possible to emphasize the difficulty in understanding the changes produced by the SARME without the aid of an associated technological evaluation (Verstraaten et al., 2010).

Another component evaluated in the present research was the distribution of stresses along the bone-supported apparatus, through the Von Mises stress. The results showed ahigh concentration of stress in the rod of the stress, between the body and the end, showing the site of greater fragility of this system. Because the anchor screws of the device are positioned to remain more neutral, no stresses transmitted to this structure were observed. Since the positioning of these screws in a real clinical situation happens differently, these screws do not act in a neutral way as seen in the present study. This may explain the intercurrences related to the devices seen by Ramieri et al., 2005, represented by the losses of the fastening screws or the device module. The authors also describe complications suchas ulcers in the palatal mucosa. In the present work we observe, when evaluating the imagesof the minimum principal stress, compression areas concentrated in the region of support ofthe platform of the device. This compression may justify the occurrence of these complications.

They could also show that for the use of the bone-supported devices, it is necessary to perform the osteotomies since they promote a dissipation of efforts for the infraorbital regions, all extension between the ENA and ENP and skull base. Some of these findings could be observed in the present research, mainly related to tensile dissipation in the palatal region and posterior region. Even the model containing only parts of the craniofacial structures modeled the comparison between different osteotomies made by de Assis et al., 2013, demonstrating the behavior of the stresses described by the authors.

These findings may explain the occurrence of complications described in the literature such as skull base fractures resulting in a carotid-cavernous fistula and also fractures in the sphenoid sinus roof, resulting in partial paralysis of the oculomotor nerve (Lanigan \& Mintz, 2002; Carneiro et al., 2013).

Although clinical studies have provided useful results, accurate and long-term evaluation of the biomechanical effects of orthopedic forces on internal bone structures, including craniofacial complex sutures, has been limited (Lee et al., 2014).

However, further studies are needed to evaluate how the behavior of maxillary bone displaced by the constant stress generated at the points of greatest tensile and compressivestress concentration could be considered, since the model simulates the reaction of these structures only in their initial movement. There are technical difficulties in creating more complex models that can contemplate their effects in the long term. Thus, it is clear the needto create models that can simulate the effects of SARME.

In general, when analyzing the results found in the literature of SARME with the effects of dental anchoring devices, we can say that the advantages with respect to the useof bone-supported devices could be observed and highlighted by the results of the present research. However, it is important to point out that these data come from the analysis of a virtual model simulation, so they should not be faithfully transported to actual clinical conditions. Since these results also 
refer only to the initial behavior of the effects of SARME, studies like these do not make very clear how the behavior of the displaced maxillary bonescould be when exposed to the constant effort generated in the points of greater concentration of traction and compression stresses.

Despite the limitations of the method, due to the simplification of the models, such as the fact that in the present model only a part of the pterygoid process was modeled, the presented results showed coherence with the findings in the literature in the analyzed aspects, showing a tendency of lower transmission of stress to the teeth of the alveolar ridge, consequently leading to a lower risk of complications. We believe although that the effects on dental inclinations shown in the present study are not yet completely ruled out bythe use of bone-supported devices, as pointed out by Koudstaal et al., 2006 and Koudstaal et al., 2009.

\section{Conclusion}

We can conclude that the transmission of stresses resulting from the use of the bone-supported expander device does not appear to be sufficient to cause significant tooth dislocation. The use of the bone-supported expander can be considered as a viable option in extreme cases where the dental movement caused by the expansion is more critical. Taking into account the optimal positioning of the device's anchor screws, the most fragile and most susceptible part of the system failure is related to the rod connecting the body to the distractor end.

\section{Acknowledgments}

The present work was financed by CAPES - Brazilian Federal Agency for Support and Evaluation of Graduate Education within the Ministry of Education of Brazil” conductedat the Bauru School of Dentistry, University of Sao Paulo.

\section{References}

Asscherickx, K., Govaerts, E., Aerts, J., \& Vande Vannet, B. (2016). Maxillary changes with bone-borne surgically assisted rapid palatal expansion: A prospective study. American journal of orthodontics and dentofacial orthopedics : official publication of the American Association of Orthodontists, its constituent societies, and the American Board of Orthodontics, 149(3), 374-383. https://doi.org/10.1016/j.ajodo.2015.08.018

Aziz, S. R., \& Tanchyk, A. (2008). Surgically assisted palatal expansion with a bone-borne self-retaining palatal expander. Journal of oral and maxillofacial surgery : official journal of the American Association of Oral and Maxillofacial Surgeons, 66(9), 1788-1793. https://doi.org/10.1016/j.joms.2008.04.017

Babacan, H., Sokucu, O., Doruk, C., \& Ay, S. (2006). Rapid maxillary expansion and surgically assisted rapid maxillary expansion effects on nasal volume. The Angle orthodontist, 76(1), 66-71. https://doi.org/10.1043/0003-3219(2006)076[0066:RMEASA]2.0.CO;2

Basdra, E. K., Zöller, J. E., \& Komposch, G. (1995). Surgically assisted rapid palatal expansion. Journal of clinical orthodontics : JCO, 29(12), 762-766

Bays, R. A., \& Greco, J. M. (1992). Surgically assisted rapid palatal expansion: an outpatient technique with long-term stability. Journal of oral and maxillofacial surgery : official journal of the American Association of Oral and Maxillofacial Surgeons, 50(2), 110-115. https://doi.org/10.1016/02782391(92)90352-Z

Bell, W. H., \& Epker, B. N. (1976). Surgical-orthodontic expansion of the maxilla. American journal of orthodontics, 70(5), 517-528. https://doi.org/10.1016/0002-9416(76)90276-1

Bishara, S. E., \& Staley, R. N. (1987). Maxillary expansion: clinical implications. American journal of orthodontics and dentofacial orthopedics : official publication of the American Association of Orthodontists, its constituent societies, and the American Board of Orthodontics, 91(1), 3-14. https://doi.org/10.1016/0889-5406(87)90202-2

Boryor, A., Hohmann, A., Wunderlich, A., Geiger, M., Kilic, F., Sander, M., Sander, C., Böckers, T., \& Günter Sander, F. (2010). In-vitro results of rapid maxillary expansion on adults compared with finite element simulations. Journal of biomechanics, 43(7), 1237-1242. https://doi.org/10.1016/j.jbiomech.2010.02.002

Carneiro, J. T., Jr, Paschoal, E. H., Carreira, A. S., \& Real, R. P. (2013). Carotid cavernous fistula after surgically assisted rapid maxillary expansion with a bone anchored appliance. International journal of oral and maxillofacial surgery, 42(3), 326-328. https://doi.org/10.1016/j.ijom.2012.10.00

Chung, C. H., \& Goldman, A. M. (2003). Dental tipping and rotation immediately after surgically assisted rapid palatal expansion. European journal of orthodontics, 25(4), 353-358. https://doi.org/10.1093/ejo/25.4.353 
Research, Society and Development, v. 11, n. 2, e49811225845, 2022

(CC BY 4.0) | ISSN 2525-3409 | DOI: http://dx.doi.org/10.33448/rsd-v11i2.25845

Assis, D. S., Ribeiro, P. D., Jr, Duarte, M. A., \& Gonçales, E. S. (2011). Evaluation of the mesio-buccal gingival sulcus depth of the upper central incisors in patients submitted to surgically assisted maxillary expansion. Oral and maxillofacial surgery, 15(2), 79-84. https://doi.org/10.1007/s10006-010-0233-x

Assis, D. S., Xavier, T. A., Noritomi, P. Y., \& Gonçales, E. S. (2014). Finite element analysis of bone stress after SARPE. Journal of oral and maxillofacial surgery : official journal of the American Association of Oral and Maxillofacial Surgeons, 72(1), 167.e1-167.e1677. https://doi.org/10.1016/j.joms.2013.06.210

Assis, D. S., Xavier, T. A., Noritomi, P. Y., Gonçales, A. G., Ferreira, O., Jr, de Carvalho, P. C., \& Gonçales, E. S. (2013). Finite element analysis of stress distribution in anchor teeth in surgically assisted rapid palatal expansion. International journal of oral and maxillofacial surgery, 42(9), $1093-1099$. https://doi.org/10.1016/j.ijom.2013.03.024

Gijt, J. P., Gül, A., Tjoa, S. T., Wolvius, E. B., van der Wal, K. G., \& Koudstaal, M. J. (2017). Follow up of surgically-assisted rapid maxillary expansion after 6.5 years: skeletal and dental effects. The British journal of oral \& maxillofacial surgery, 55(1), 56-60. https://doi.org/10.1016/j.bjoms.2016.09.002

Gauthier, C., Voyer, R., Paquette, M., Rompré, P., \& Papadakis, A. (2011). Periodontal effects of surgically assisted rapid palatal expansion evaluated clinically and with cone-beam computerized tomography: 6-month preliminary results. American journal of orthodontics and dentofacial orthopedics : official publication of the American Association of Orthodontists, its constituent societies, and the American Board of Orthodontics, 139(4 Suppl), S117S128. https://doi.org/10.1016/j.ajodo.2010.06.022

Gerlach, K. L., \& Zahl, C. (2005). Surgically assisted rapid palatal expansion using a new distraction device: report of a case with an epimucosal fixation. Journal of oral and maxillofacial surgery : official journal of the American Association of Oral and Maxillofacial Surgeons, 63(5), 711-713. https://doi.org/10.1016/j.joms.2004.12.017

Gonçales ES, Assis DSFR, Capelozza ALA, Alvares LC. (2007). Estudo radiográfico digital indireto do efeito da expansão de maxila cirurgicamente assistida (EMCA) sobreo septo nasal. R Dental Press Ortodon Ortop Facial.; 12(5):85-91. https://doi.org/10.1590/S1415-54192007000500011

Gonçales ES. (2011). Análise da distribuição das tensões dentárias em maxila submetidaa expansão cirurgicamente assistida [Livre Docência]. Faculdade de Odontologia de Bauru - USP. https://doi.org/10.11606/T.25.2012.tde-13032012-092604

Haas, A.J. (1961) Rapid expansion of the maxillary dental arch and nasal cavity by opening of the midpalatal suture. The Angle Orthodontics, 31, 73-90

Holzinger, D., Carvalho, P., Dos Santos, J. C., Wagner, F., Gabrielli, M., Gabrielli, M., \& Filho, V. (2021). Bone formation after surgically assisted rapid maxillary expansion: comparison of 2 distraction osteogenesis protocols. Oral surgery, oral medicine, oral pathology and oral radiology, S2212-4403(21)00488-0. Advance online publication. https://doi.org/10.1016/j.oooo.2021.06.013

Jafari, A., Shetty, K. S., \& Kumar, M. (2003). Study of stress distribution and displacement of various craniofacial structures following application of transverse orthopedic forces--a three-dimensional FEM study. The Angle orthodontist,73(1), 12-20. https://doi.org/10.1043/00033219(2003)073<0012:SOSDAD>2.0.CO;2

Kilic, E., Kilic, B., Kurt, G., Sakin, C., \& Alkan, A. (2013). Effects of surgically assisted rapid palatal expansion with and without pterygomaxillary disjunction on dental and skeletal structures: a retrospective review. Oral surgery, oral medicine, oral pathology and oral radiology, 115(2), 167-174. https://doi.org/10.1016/j.00oo.2012.02.026

Koudstaal, M. J., van der Wal, K. G., Wolvius, E. B., \& Schulten, A. J. (2006). The Rotterdam Palatal Distractor: introduction of the new bone-borne device and report of the pilot study. International journal of oral and maxillofacial surgery, 35(1), 31-35. https://doi.org/10.1016/j.ijom.2005.07.002

Koudstaal, M. J., Wolvius, E. B., Schulten, A. J., Hop, W. C., \& van der Wal, K. G. (2009). Stability, tipping and relapse of bone-borne versus tooth-borne surgically assisted rapid maxillary expansion; a prospective randomized patient trial. International journal of oral and maxillofacial surgery, 38(4), 308315. https://doi.org/10.1016/j.ijom.2009.02.012

Lanigan, D. T., \& Mintz, S. M. (2002). Complications of surgically assisted rapid palatal expansion: review of the literature and report of a case. Journal of oral and maxillofacial surgery : official journal of the American Association of Oral and Maxillofacial Surgeons,60(1), 104-110. https://doi.org/10.1053/joms.2002.29087

Lee, S. C., Park, J. H., Bayome, M., Kim, K. B., Araujo, E. A., \& Kook, Y. A. (2014). Effect of bone-borne rapid maxillary expanders with and without surgical assistance on the craniofacial structures using finite element analysis. American journal of orthodontics and dentofacial orthopedics : official publication of the American Association of Orthodontists, its constituent societies, and the American Board of Orthodontics, 145(5), 638-648. https://doi.org/10.1016/j.ajodo.2013.12.029

Möhlhenrich, S. C., Ernst, K., Peters, F., Kniha, K., Chhatwani, S., Prescher, A., Danesh, G., Hölzle, F., \& Modabber, A. (2021). Immediate dental and skeletal influence of distractor position on surgically assisted rapid palatal expansion with or without pterygomaxillary disjunction. International journal of oral and maxillofacial surgery, 50(5), 649-656. https://doi.org/10.1016/j.ijom.2020.10.003

Ramieri, G. A., Spada, M. C., Austa, M., Bianchi, S. D., \& Berrone, S. (2005). Transverse maxillary distraction with a bone-anchored appliance: dentoperiodontal effects and clinical and radiological results. International journal of oral and maxillofacial surgery, 34(4), $357-363$. https://doi.org/10.1016/j.ijom.2004.10.011

Schwarz, G. M., Thrash, W. J., Byrd, D. L., \& Jacobs, J. D. (1985). Tomographic assessment of nasal septal changes following surgical-orthodontic rapid maxillary expansion. American journal of orthodontics, 87(1), 39-45. https://doi.org/10.1016/0002-9416(85)90172-1

Seeberger, R., Kater, W., Davids, R., \& Thiele, O. C. (2010). Long term effects of surgically assisted rapid maxillary expansion without performing osteotomy of the pterygoid plates. Journal of cranio-maxillo-facial surgery : official publication of the European Association for Cranio-Maxillo-Facial Surgery, 38(3), 175-178. https://doi.org/10.1016/j.jcms.2009.07.003 
Research, Society and Development, v. 11, n. 2, e49811225845, 2022

(CC BY 4.0) | ISSN 2525-3409 | DOI: http://dx.doi.org/10.33448/rsd-v11i2.25845

Shetty, P., Hegde, A. M., \& Rai, K. (2009). Study of stress distribution and displacement of the maxillary complex following application of forces using jackscrew and nitanium palatal expander 2--a finite element study. The Journal of clinical pediatric dentistry,34(1), 87-93. https://doi.org/10.17796/jcpd.34.1.dv5100j371184087

Shetty, V., Caridad, J. M., Caputo, A. A., \& Chaconas, S. J. (1994). Biomechanical rationale for surgical-orthodontic expansion of the adult maxilla. Journal of oral and maxillofacial surgery : official journal of the American Association of Oral and Maxillofacial Surgeons, 52(7), 742-751. https://doi.org/10.1016/0278-2391(94)90492-8

Verstraaten, J., Kuijpers-Jagtman, A. M., Mommaerts, M. Y., Bergé, S. J., Nada, R. M., Schols, J. G., \& Eurocran Distraction Osteogenesis Group (2010). A systematic review of the effects of bone-borne surgical assisted rapid maxillary expansion. Journal of cranio-maxillo-facial surgery : official publication of the European Association for Cranio-Maxillo-Facial Surgery, 38(3), 166-174. https://doi.org/10.1016/j.jcms.2009.06.006

Williams, B. J., Currimbhoy, S., Silva, A., \& O'Ryan, F. S. (2012). Complications following surgically assisted rapid palatal expansion: a retrospective cohort study. Journal of oral and maxillofacial surgery : official journal of the American Association of Oral and Maxillofacial Surgeons, 70(10), 23942402. https://doi.org/10.1016/j.joms.2011.09.050

Zandi, M., Miresmaeili, A., Heidari, A., \& Lamei, A. (2016). The necessity of pterygomaxillary disjunction in surgically assisted rapid maxillary expansion: A short-term, double-blind, historical controlled clinical trial. Journal of cranio-maxillo-facial surgery : official publication of the European Association for Cranio-Maxillo-Facial Surgery, 44(9), 1181-1186. https://doi.org/10.1016/j.jcms.2016.04.026 